\title{
The influence of antihypertensive treatment over the incidence of cerebral vascular disease
}

\author{
D. G. BEEVERS* \\ M.B., M.R.C.P. \\ M. HAMilton \\ M.D., F.R.C.P.
}

\author{
M. J. FAIRMAN \\ M.B., M.R.C.P. \\ J. E. HARPur \\ M.B., B.S.
}

\section{Chelmsford Group of Hospitals}

\section{Summary}

The incidence of stroke in a group of 499 treated hypertensive patients was closely related to the adequacy of control of hypertension. This trend was independent of the level of diastolic blood pressure at presentation, and differed markedly from the incidence of myocardial infarction and angina pectoris which did not vary with adequacy of control.

\section{Introduction}

The benefits of antihypertensive therapy in reducing the mortality from certain complications of hypertension are now well established. Improved prognosis in respect of the malignant phase was demonstrated by Morrison (1953) and quickly confirmed by Rosenheim (1954), Schroeder (1954) and McMichael \& Murphy (1955). Simultaneously, Smirk (1953) showed an improved prognosis in respect of congestive cardiac failure amongst treated hypertensive patients. Although the benefits of treating non-malignant hypertension are less welldefined, all would now agree that treatment of hypertension in the young and middle-aged is effective in lowering the mortality rate (Hodge, McQueen \& Smirk, 1961) and in the prevention of complications of hypertension, particularly stroke (Hamilton, Thompson \& Wisniewski, 1964; Veterans Administration Co-operative Study Group, 1967). In this study we review the incidence of stroke and certain other vascular complications of hypertension amongst a group of treated hypertensive subjects, and correlate the findings with the quality of control of hypertension.

\section{Patients and methods}

The patients were drawn from a total of 499 treated hypertensive subjects in whom there was no evidence of established cerebral vascular disease at

Requests for reprints: Medical Academic Unit, Chelmsford and Essex Hospital, London Road, Chelmsford, Essex.

* Present address: MRC Blood Pressure Unit, Western Infirmary, Glasgow, W.I. the time of presentation. The need for treatment was determined solely by the severity of the hypertension or its complications. Most patients received a thiazide diuretic, either alone or in combination with other antihypertensive agents such as methyldopa, bethanidine, clonidine, debrisoquine, or in the earlier days, ganglion blocking agents. All patients were followed up in the out-patient clinic, at which time they were seen by the same physician or his registrar, and the blood pressures were recorded in the lying and standing positions using the standard sphygmomanometer. The control of blood pressure during the period of follow up has been graded in an arbitrary manner as follows:

Good control; mean standing diastolic blood pressure less than $100 \mathrm{mmHg}$.

Fair control; mean standing diastolic blood pressure between 100 and $109 \mathrm{mmHg}$.

Poor control; mean standing diastolic blood pressure $110 \mathrm{~mm} \mathrm{Hg}$ or more.

The patients were followed for periods of up to 12 years with a mean follow up time of 48 months, during which time seventy-four of them $(14.8 \%)$ developed a stroke, of whom forty-three were male, thirty-one female.

The type of stroke was classified clinically as follows:

(1) Subarachnoid haemorrhage; diagnosis confirmed by examination of the cerebrospinial fluid (three patients).

(2) Transient cerebral ischaemic attack-a transient focal disturbance-recovering fully within $24 \mathrm{hr}$ (seven patients).

(3) Major persistent stroke; a hemiplegia or hemianaesthesia with incomplete recovery producing some persistent impairment of function of one or both limbs (thirty-six patients).

(4) Minor persistent stroke; leaving some impairment of function so trivial as not to disable the patient during his normal activities (twenty-two patients). 
(5) Mental change; progressive mental deterioration without focal neurological signs (six patients).

The mean age at presentation of the patients who later developed a stroke was 55 years, and there was no significant difference in this respect between the males and the females within any of the groups of control of blood pressure. The patients showed the usual mixed aetiology of the hypertension and the complications found at presentation were those usually seen in any group of hypertensive subjects of similar size (Table 1).

The mean standing diastolic blood pressure at presentation of those patients who later developed a stroke was $111 \mathrm{mmHg}$ in the good control group, $123 \mathrm{mmHg}$ in the fair control group, and $135 \mathrm{mmHg}$ in the poor control group (Table 2).

Of the seventy-four patients who developed a stroke during the period of follow-up, early death (i.e. within 3 months) occurred in twenty-eight patients, in nineteen of these as a result of the stroke, and in nine from other causes. Ten patients were lost to follow-up and thirty-six have continued to attend the out-patient clinic.

\section{Results}

Of the 499 hypertensive patients under treatment, there were 301 with good control of hypertension, of whom twenty-two developed a stroke $(7 \%)$. There were 149 patients in whom control of the hypertension was considered fair, of whom twenty-five developed a stroke $(17 \%)$, and there were forty-nine patients in whom the control of the hypertension was poor and of these twenty-seven developed a stroke $(55 \%)$ (Table 3, Fig. 1).

Not only was the incidence of stroke much lower in those with good control of the hypertension, but

TABLE 1. Complications at presentation (seventyfour patients)

\begin{tabular}{lrr}
\hline & No. $\%$ \\
\hline Left ventricular enlargement & & \\
$\quad$ (clinical, cardiographic, or radiological) & 45 & 61 \\
Blood urea $>40 \mathrm{mg} / 100 \mathrm{ml}$ & 21 & 28 \\
Cardiac failure & 16 & 22 \\
Previous myocardial infarction & 10 & 14 \\
Angina pectoris & 6 & 8 \\
Intermittent claudication & 1 & 1 \\
\hline
\end{tabular}

TABLE 2. Mean standing diastolic blood pressure at presentation $(\mathrm{mmHg})$

\begin{tabular}{|c|c|c|c|}
\hline & \multicolumn{3}{|c|}{ Subsequent Control of Hypertension } \\
\hline & Good & Fair & Poor \\
\hline $\begin{array}{l}\text { Males } \\
\text { Females } \\
\text { All }\end{array}$ & $\begin{array}{l}109.4 \pm 13.8 \\
115.0 \pm 5.0 \\
110.5 \pm 12.6\end{array}$ & $\begin{array}{l}122 \cdot 9 \pm 21 \cdot 6 \\
122 \cdot 5 \pm 20 \cdot 7 \\
122 \cdot 8 \pm 22 \cdot 2\end{array}$ & $\begin{array}{l}135 \cdot 4 \pm 10 \cdot 2 \\
134 \cdot 1 \pm 10 \cdot 1 \\
134 \cdot 8 \pm 10 \cdot 5\end{array}$ \\
\hline
\end{tabular}

TABLE 3. Incidence of complications within groups divided by control of hypertension

\begin{tabular}{|c|c|c|c|c|c|c|c|c|}
\hline & \multicolumn{8}{|c|}{ Control of hypertension } \\
\hline & \multicolumn{2}{|c|}{ Good } & \multicolumn{2}{|c|}{ Fair } & \multicolumn{2}{|c|}{ Poor } & \multicolumn{2}{|c|}{ Overall } \\
\hline & No. & $\%$ & No. & $\%$ & No. & $\%$ & No. & $\%$ \\
\hline $\begin{array}{l}\text { Stroke } \\
\text { Myocardial }\end{array}$ & $22^{*}$ & $7 \cdot 3$ & $25^{*}$ & $16 \cdot 8$ & $27^{*}$ & $55 \cdot 1$ & 74 & $14 \cdot 8$ \\
\hline $\begin{array}{l}\text { infarction } \\
\text { Angina }\end{array}$ & 2 & 0.7 & 2 & $1 \cdot 3$ & 1 & $2 \cdot 0$ & 5 & $1 \cdot 0$ \\
\hline $\begin{array}{l}\text { pectoris } \\
\text { Cardiac }\end{array}$ & 4 & $1 \cdot 3$ & 3 & $2 \cdot 0$ & 1 & $2 \cdot 0$ & 8 & $1 \cdot 6$ \\
\hline failure & 2 & 0.7 & 3 & $2 \cdot 0$ & 4 & $8 \cdot 2$ & 9 & $1 \cdot 8$ \\
\hline
\end{tabular}

$* \chi^{2}$ for trend (1 d.f.) $42 \cdot 57, P=<0.001$.

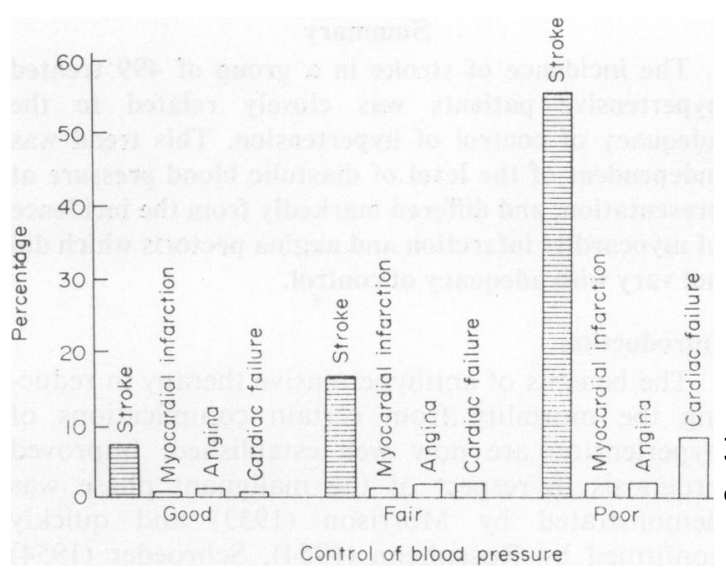

Fig. 1. Incidence of complications.

also the proportion of patients developing their stroke within 2 years of starting treatment differed greatly in the three groups of control. Of those with good control of hypertension only $2 \%$ of the patients had their stroke within 2 years. Of those with fair control of hypertension $5 \%$, and of those with poor control $23 \%$, developed their stroke during the same period.

Although this provides strong evidence that the incidence of stroke is closely related to the degree of control of hypertension, an alternative possibility is that the incidence of stroke depends on the severity of the hypertension at the time of starting treatment. To investigate this further the patients were divided according to the level of blood pressure recorded at presentation (Table 4). Within these divisions the incidence of stroke was considered in relation to the subsequent control of blood pressure in the way already outlined. Although this shows a higher incidence of stroke in those patients with the highest levels of presenting diastolic blood pressure, the increased incidence of stroke amongst those with poor control of hypertension is even more apparent, 
TABLE 4. Incidence of stroke in groups of hypertensive patients divided by presenting blood pressure and subsequent control of hypertension

\begin{tabular}{|c|c|c|c|c|}
\hline $\begin{array}{c}\text { Presenting } \\
\text { diastolic } \\
\text { blood pressure } \\
(\mathrm{mmHg})\end{array}$ & No. & $\begin{array}{l}\text { Subsequent } \\
\text { control of } \\
\text { hypertension } \\
\text { (and no.) }\end{array}$ & $\begin{array}{c}\text { Number } \\
\text { (and \%) } \\
\text { developing } \\
\text { a stroke }\end{array}$ & $\begin{array}{l}\chi^{2} \text { for trend } \\
\text { (1 d.f.) }\end{array}$ \\
\hline$<120$ & 110 & $\begin{array}{l}\text { Good (78) } \\
\text { Fair (23) } \\
\text { Poor (9) }\end{array}$ & $\begin{array}{l}2(3 \%) \\
4(17 \%) \\
4(44 \%)\end{array}$ & $19 \cdot 830^{*}$ \\
\hline \multirow[t]{2}{*}{$120-130$} & 271 & $\begin{array}{l}\text { Good (163) } \\
\text { Fair (85) } \\
\text { Poor (23) }\end{array}$ & $\begin{array}{r}18(11 \%) \\
9(11 \%) \\
11(48 \%)\end{array}$ & $12 \cdot 300^{*}$ \\
\hline & 118 & $\begin{array}{l}\text { Good (60) } \\
\text { Fair (41) } \\
\text { Poor (17) }\end{array}$ & $\begin{array}{c}2(3 \%) \\
12(41 \%) \\
12(70 \%)\end{array}$ & $36 \cdot 000^{*}$ \\
\hline
\end{tabular}

to a high order of statistical significance. This indicates a close correlation between control of blood pressure and incidence of stroke and that the most important factor in prevention of stroke is the quality of control of the hypertension after starting treatment rather than its manometric severity at presentation.

The incidence of heart failure in those patients with good control of hypertension was $1 \%$ compared with $8 \%$ in those patients with poor control. There was, however, little difference in the incidence of myocardial infarction or of angina pectoris in the three groups of control of blood pressure (Table 3, Fig. 1).

\section{Discussion}

In the majority of the patients under treatment for hypertension it was possible to maintain good control with standing diastolic blood pressures maintained below $100 \mathrm{mmHg}$. However, in $40 \%$ of the patients in the present series, this ideal could not be achieved and in $10 \%$ it proved impossible to maintain any satisfactory form of control. There are many possible reasons for this, and it is not the purpose of this paper to investigate these reasons, but certainly the presenting diastolic blood pressure was lower in those who were subsequently well controlled (Table 2 ) and so possibly they were suffering from a less severe form of hypertension.

Although Table 4 does suggest an increasing liability to stroke with rising levels of diastolic blood pressure before starting treatment, the difference in the incidence of stroke between the three groups of control of blood pressure is even more apparent, and this is strong evidence that the incidence of stroke is more closely related to the adequacy of treatment rather than the severity of the hypertension at presentation.

The demonstration by Ross Russell (1963) of the miliary aneurysms affecting the small perforating cerebral vessels, originally described by Charcot \& Bouchard (1868), leaves no doubt that this is the lesion principally responsible for cerebral haemorrhage occurring in hypertensive subjects. The incidence of stroke in this series contrasts strikingly with that of other vascular complications and Fig. 1 shows that the adequacy of antihypertensive treatment has little apparent influence over the incidence of angina and myocardial infarction. This discrepancy implies a different vascular lesion responsible for cerebral and coronary artery disease in hypertensive subjects and it is reasonable to suppose that the benefits of antihypertensive therapy result from the reduction of either the formation or the rupture of these aneurysms.

In patients presenting with severe manometric hypertension the value of early treatment in reducing the incidence of strokes has been well defined by therapeutic trials reported almost a decade ago (Hamilton et al., 1964). The present study indicates that treatment of hypertension, particularly if that treatment is effective in maintaining a mean level of diastolic blood pressure below $100 \mathrm{mmHg}$, greatly reduces the incidence of cerebral vascular attacks; in this study from $55 \%$ in those with poor control to $7 \%$ in those with good control.

\section{Acknowledgments}

We are greatly indebted to Professor G. Rose for helpful advice and criticism and to the Chelmsford Medical Education and Research Trust for the provision of the Research Registrar's salary. and to Mrs D. Bennett and Mrs P. Ruddock for secretarial help.

\section{References}

Charcot, J.M. \& BouchaRd, C. (1868) Nouvelles recherches sur la pathogénie de l'hémorrhagie cérébrale. Archives of Physiology, 1, 110, 643.

Hamilton, M., Thompson, E.N. \& Wisniewski, T.K.M. (1964) The role of blood-pressure control in preventing complications of hypertension. Lancet, i, 235.

Hodge, J. V., McQueEn, E.G. \& SMIRK, H. (1961) Results of hypotensive therapy in arterial hypertension. British Medical Journal, 1, 1.

McMichael, J. \& MurPhy, E.A. (1955) Methonium treatment of severe and malignant hypertension. Journal of Chronic Diseases, 1, 527.

Morrison, B. (1953) Parenteral hexamethonium in hypertension. British Medical Journal, 1, 1291.

Rosenheim, M.L. (1954) The treatment of severe hypertension. British Medical Journal, 2, 1181.

Russell, R.W.R. (1963) Observations on intracerebral aneurysms. Brain, 86, 425 .

SCHROEDER, H.A. (1954) Management of arterial hypertension. American Journal of Medicine, 17, 540.

SMirk, F.H. (1953) Practical details of the treatment of hypertension by hexamethonium salts and by pentamethylene 1:5 bis-N-(N-methylpyrollidinium bitartrate (M \& B 2050A). New Zealand Medical Journal, 52, 325.

Veterans Administration Co-operative Study Group in ANTIHYPERTENSIVE AGENTS (1967) Effects of treatment on morbidity in hypertension: results in patients with diastolic blood pressures averaging 115-129 mm Hg. Journal of the American Medical Associaiion, 202, 1028. 